
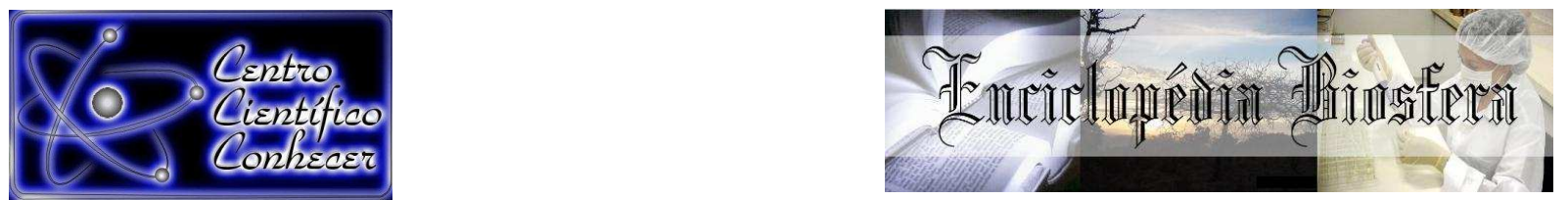

\title{
DESEMPENHO OPERACIONAL DE PULVERIZADOR AUTOPROPELIDO DE BARRAS NO MUNICÍPIO DE SINOP- MT
}

\author{
Thiago Martins Machado ${ }^{1}$, Danilo Gonçalves Batista Queiroz ${ }^{2}$, Étore Francisco \\ Reynaldo $^{3}$ \\ ${ }^{1}$ Professor Doutor do Instituto de Ciências Agrárias e Ambientais da Universidade \\ Federal de Mato Grosso - Campus Sinop - Sinop - MT - Brasil \\ (tm.machado@hotmail.com) \\ ${ }^{2}$ Graduando em Engenharia Agrícola e Ambiental da Universidade Federal de Mato \\ Grosso - Sinop - MT - Brasil \\ ${ }^{3}$ Pesquisador da Fundação Agrária de Pesquisa Agropecuária \\ (reynaldo@agraria.com.br) - Entre Rios - PR - Brasil
}

Recebido em: 08/09/2015 - Aprovado em: 14/11/2015 - Publicado em: 01/12/2015

DOI: http://dx.doi.org/10.18677/Enciclopedia_Biosfera_2015_128

\begin{abstract}
RESUMO
A análise operacional para aplicação de defensivos agrícolas é importante para a escolha do equipamento mais adequado, permitindo rapidez na aplicação e racionalização de custos, sem prejuízo da eficiência do controle fitossanitário. 0 objetivo do trabalho foi avaliar o desempenho operacional de um pulverizador autopropelido de barras no município de Sinop - MT. A avaliação foi realizada a campo em dois talhões, sendo à aplicação realizada com o pulverizador autopropelido John Deere 4730. Através de uma planilha, cronômetros, e aparelho receptor GPS, foram coletados os dados em campo. Foram utilizados diferentes tipos de equações para cálculo do desempenho operacional da máquina e simulações de campo. Os tempos de reabastecimento do pulverizador e de deslocamento para reabastecimento foram diferentes entre os talhões, e representaram alta influência no tempo de interrupção sendo os mais impactantes. O rendimento de campo operacional ficou dentro do recomendado, mas ainda podendo ser melhorado.
\end{abstract}

PALAVRAS-CHAVE: Capacidade de campo efetiva, tecnologia de aplicação, rendimento operacional.

\section{OPERATING PERFORMANCE SPRAY SELF-PROPELLED IN CITY OF SINOP- MT}

\begin{abstract}
The operational analysis for application of pesticides is important to choose the most suitable equipment, enabling fast implementation and rationalization costs, subject to phytosanitary control efficiency. The objective was to evaluate the operating performance of a self-propelled sprayer bars in the city of Sinop - MT. The evaluation was conducted in two field plots, and the application performed with the self-propelled sprayer John Deere 4730. Using a spreadsheet, timers, and GPS receiver, the data were collected in the field. They used different types of equations to calculate the
\end{abstract}


operational performance of the machine and field simulations. The refueling times spray and displacement for refueling were different between the plots, and represented high influence on the dwell time being the most impressive. The operating field performance was within recommended levels, but still can be improved.

KEYWORDS: Effective field capacity, application technology, efficiency.

\section{INTRODUÇÃO}

O aumento da população mundial traz a necessidade de uma agricultura cada vez mais eficiente e competitiva. Com a exploração de áreas agrícolas cada vez maiores, a necessidade do controle de pragas e doenças se tornou mais eminente e a quantidade de aplicações de produtos químicos maiores.

O grande número de pragas e doenças na cultura está entre os principais fatores de risco e causam redução na produção, para evitar isso é necessária à aplicação de defensivos, que resulta no aumento dos custos de produção (VIEIRA, 2013; PERES, 2014). A tecnologia de aplicação de defensivos agrícolas tem por objetivo propiciar a correta colocação do produto biologicamente ativo no alvo, em quantidade necessária, de forma econômica, com o mínimo de contaminação de outras áreas (MATUO, 1990).

Para JUNIOR et al. (2013), o uso do conceito da tecnologia de aplicação ao desempenho operacional dos equipamentos a campo, resultam em uma economia de recursos naturais e financeiros, contribuindo para a qualidade da pulverização. Através desses estudos podem resultar em reduções de volumes de aplicação, maiores ganhos em hectares tratados em um mesmo período de tempo, economia de combustíveis, redução na deriva, dentre outros.

MATUO (1990) define que devido ao alto custo de transporte da água ao campo e a perda de tempo para reabastecimento do pulverizador, as práticas requerem menor volume de aplicação, com o intuito de diminuir os custos e aumentar a capacidade operacional. Mas é necessário cuidado quando diminui a quantidade de produto, que para alcançar a cobertura e deposição satisfatória é necessário diminuir o tamanho da gota, o que aumenta o risco de perder produto pela evaporação ou deriva (PERES, 2014).

Segundo COSTA (2009) é possível reduzir em grande parte o uso de agrotóxicos nas lavouras, usando-se volume de água menor por hectare, para isso o pulverizador deve ser bem regulado para que não tenha desperdício de produto químico. Segundo o mesmo autor, a redução do volume de pulverização leva a uma tecnologia mais apurada, de acordo com quem está envolvido na parte técnica da aplicação e quem construiu o equipamento.

A eficiência de pulverização é dependente da estrutura fundiária e dos tempos perdidos nas manobras, no reabastecimento, na calibração e na limpeza dos bicos pulverizadores, dentre outros. É um fator de extrema importância que afeta diretamente a capacidade de campo operacional (BAIO et al., 2004). Conforme as evidências, o objetivo do trabalho foi avaliar o desempenho operacional de um pulverizador autopropelido no município de Sinop - MT. 


\section{MATERIAL E METÓDOS}

O trabalho foi realizado na região norte do estado de Mato Grosso, na Fazenda Aeroporto no município de Sinop-MT. A sede da propriedade com latitude de $11^{\circ}$ 53,8' $\mathrm{S}$, longitude $55^{\circ} 36,18^{\prime} \mathrm{W}$ e altitude média de $373 \mathrm{~m}$.

A aplicação de defensivos foi realizada na cultura do algodão, onde estava em pleno desenvolvimento vegetativo, com volume de aplicação de $60 \mathrm{~L} \mathrm{ha}{ }^{-1}$. A coleta de dados foi realizada para dois talhões da fazenda. O primeiro denominado talhão 29 , com área tratada de 189,9 ha, e o talhão 38 com área tratada de 128,9 ha.

A aplicação foi realizada com o pulverizador autopropelido marca John Deere 4730 (DEERE, 2015) (Figura 1), e suas especificações são citadas na Tabela 1.

TABELA 1 - Especificações técnicas do pulverizador John Deere 4730.

\begin{tabular}{lc}
\hline \multicolumn{2}{c}{ Especificações técnicas } \\
\hline Potência do motor (cv) & 245 \\
Capacidade do reservatório de calda $(\mathrm{L})$ & 3.028 \\
Barra de pulverização $(\mathrm{m})$ & 30 \\
Espaçamento entre bicos $(\mathrm{m})$ & 0,50 \\
Vão livre $(\mathrm{m})$ & 1,57 \\
Capacidade do tanque de combustível $(\mathrm{L})$ & 503 \\
Transmissão & Hidrostática $4 \times 4$ \\
Monitor & GS3 2630 \\
Receptor de GPS & SF3000 \\
\hline
\end{tabular}

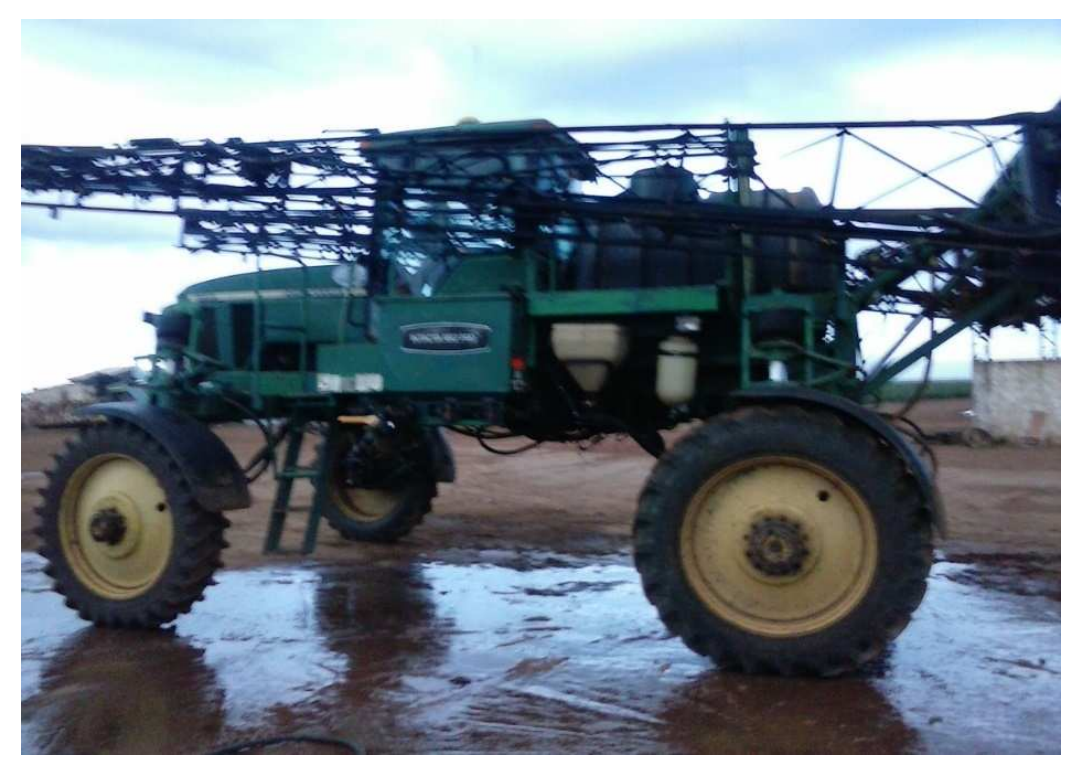

FIGURA 1 - Pulverizador Autopropelido John Deere 4730. 
Para mensuração do desempenho operacional do pulverizador, foi feita uma planilha com auxílio do aplicativo Excel, onde estavam contidos os dados que foram anotados em campo, como velocidades e tempos.

Dois cronômetros foram usados para marcar os tempos de deslocamento do pulverizador aplicando no talhão, manobras e reabastecimentos. Um aparelho receptor de GPS marca Garmin ${ }^{\circledR}$ modelo Vista foi colocado na cabine da máquina para marcação de rotas com intervalo de tempo de $10 \mathrm{~s}$, onde ficou armazenada sua localização, velocidade e outras informações.

O pulverizador sempre era regulado, e realizada a limpeza no final do dia anterior, para evitar perdas da jornada de trabalho. O defensivo agrícola, utilizado foi Difenoconazol (Score ${ }^{\circledR}$ ), um fungicida sistêmico do grupo químico triazol, junto com pesticida à base de piretróide. A água para calda era de um reservatório com capacidade de $10.000 \mathrm{~L}$. Com auxílio de uma bomba elétrica com vazão de $470 \mathrm{~L} \mathrm{~min}^{-1}$ abastecia o reservatório do pulverizador e anotava-se tempo de abastecimento na planilha.

O trabalho de pulverização foi iniciado no talhão 29 , que fica próximo a área da sede com uma distância média de $200 \mathrm{~m}$. A velocidade da máquina era identificada no monitor do pulverizador e após o termino do talhão era conferida com os dados coletados pelo GPS de navegação. $\mathrm{Na}$ aplicação do talhão 29 , foram realizados quatro reabastecimentos do reservatório de calda no local próximo da sede.

Logo após a aplicação no talhão 29, o pulverizador se deslocou para o talhão 38, e foi reabastecido o reservatório em um segundo local "carreador" ao lado da área cultivada. Nesse ponto estava a carreta pipa com água, tracionadas por trator Massey Ferguson modelo 275, foi acoplado a TDP do mesmo, uma bomba de vazão $330 \mathrm{~L}$ min 1, para impulsionar o líquido pelas mangueiras até o reservatório do pulverizador.

Aconteceram três reabastecimentos do pulverizador para a aplicação no talhão 38, ao final da operação na área, foi finalizado o trabalho. Em posse dos dados coletados em campo, foi utilizada à metodologia proposta por (MIALHE, 1974) e (MATUO,1990) e descrita seguir pelas equações, como parâmetro para o desempenho operacional analisado.

Capacidade de Campo Efetiva ( $\mathrm{CcE}$ ) é a capacidade efetivamente demonstrada pela máquina. O tempo de produção é o tempo no qual a máquina efetivamente foi utilizada na operação. Para o cálculo da capacidade de campo efetiva (ha $\mathrm{h}^{-1}$ ) foi usada à equação (1).

$\mathrm{CcE}=\frac{\text { Área Tratada }}{\text { Tempo de produçäo }}$

Capacidade de Campo Operacional $(\mathrm{CcO})$ é a capacidade da máquina observada em condições reais de operação, onde se levam em conta todos os efeitos dos fatores operacionais. Para o cálculo da capacidade operacional no trabalho foi usado dois diferentes métodos. No primeiro método (Método 1) é mais utilizado na literatura, foi considerado o tempo máquina e seus fatores, que é defino por (MIALHE, 1974) e também mencionado por MATUO (1990).

A capacidade de campo operacional $\left(\mathrm{ha}^{-1}\right.$ ) foi calculada de acordo com a ENCICLOPÉDIA BIOSFERA, Centro Científico Conhecer - Goiânia, v.11 n.22; p.878 2015 
equação (2).

$\mathrm{CcO}=\frac{\text { Area Tratada }}{\text { Termpo máquina }}$

O tempo máquina (TM), (Equação 3) é constituído por:

$\mathrm{TM}=\mathrm{TPe}+\mathrm{TI}+\mathrm{TPr}$

onde:

TPe = tempo de preparo, consumido no preparo da máquina para entrar em operação e para deixá-la em condições de ser armazenada no galpão após a operação;

$\mathrm{TI}=$ tempo de interrupção, aquele gasto em interrupções decorrentes do próprio trabalho da máquina quando em operação em campo;

$\operatorname{TPr}=$ tempo de produção, aquele efetivamente consumido no trabalho para o qual a máquina foi projetada.

O tempo de interrupção (TI) (Equação 4) é representado por:

$\mathrm{TI}=\mathrm{Tr}+\mathrm{Td}+\mathrm{TV}$

onde:

$\mathrm{Tr}=$ tempo de reabastecimento do reservatório do pulverizador;

$\mathrm{Td}=$ tempo de deslocamento, representado pelo tempo no qual a máquina se desloca, indo para o ponto de abastecimento ou vindo deste ponto até o ponto de retoma do trabalho interrompido;

$\mathrm{Tv}=$ tempo de virada, representado pelo tempo gasto em virada na cabeceira de cada faixa de aplicação.

O segundo método (Método 2) é proposto por (MATUO, 1990) e definido como Logística da Pulverização, analisando uma operação de pulverização, onde se utiliza pulverizador com barra. O tempo t necessário para se pulverizar um hectare foi calculado pela equação (5).

$\mathrm{t}=\frac{10000}{\mathrm{VpL}}+\frac{10000 \mathrm{TV}}{\mathrm{CL}}+\frac{\mathrm{dV}}{\mathrm{Vd} \mathrm{Ca}}+\frac{\mathrm{TrV}}{\mathrm{Ca}}$

onde:

$\mathrm{t}=$ tempo para pulverizar 1 hectare $\left(\operatorname{min~ha}^{-1}\right)$;

$\mathrm{Vp}=$ velocidade de pulverização $\left(\mathrm{m} \mathrm{min}^{-1}\right)$;

$\mathrm{L}=$ largura da faixa de pulverização $(\mathrm{m})$;

Tv = tempo de virada ( $\min )$;

$\mathrm{C}=$ comprimento da faixa de tratamento $(\mathrm{m})$;

$\mathrm{d}=$ distância total percorrida para cada reabastecimento $(\mathrm{m})$;

$\mathrm{V}=$ volume de pulverização $\left(\mathrm{L} \mathrm{ha}^{-1}\right)$;

$\mathrm{Vd}=$ velocidade de deslocamento para reabastecimento $\left(\mathrm{m} \mathrm{min}^{-1}\right)$;

$\mathrm{Ca}=$ capacidade do tanque $(\mathrm{L})$;

$\mathrm{Tr}=$ tempo de reabastecimento do tanque $(\mathrm{min})$.

Para os cálculos da capacidade de campo operacional (ha $\mathrm{h}^{-1}$ ) pela logística da pulverização foi usada a equação (6).

$\mathrm{CcO}=\frac{60}{\mathrm{t}}$

A capacidade de campo operacional representa uma fração da capacidade efetiva, portanto, ela é sempre menor, uma vez que considera todas as interrupções durante a 
operação. Essa relação foi calculada através do rendimento de campo efetivo (\%) e está na equação (7).

$\operatorname{RcE}=\frac{\operatorname{CcO}}{\operatorname{CcE}} 100$

\section{Análise dos Dados}

Os dados coletados em campo foram descarregados e trabalhados por meio de planilha eletrônica onde foi calculada a capacidade efetiva e operacional de cada talhão, a eficiência de campo, como também para logística de pulverização. Foram descarregados os dados do aparelho Receptor de GPS Marca Garmin ${ }^{\circledR}$ Vista pelo software GPS TrackMaker onde foram adquiridas informações como comprimento de cada amostra, velocidade em cada ponto, localização geográfica, tempos das atividades.

Toda a área de interesse do trabalho foi detalhada e representada para o estudo com os dados trabalhados no TrackMaker, foi possível através de uma ferramenta no software, visualizar a área no GOOGLE EARTH ${ }^{\circledR}$ (Figura 2). Esse processo ajudou na interpretação das informações e serviu de parâmetro para análise.

Na Figura 2 é identificado como azul escuro os pontos onde o pulverizador aplicou nos talhões. Em cor mais clara é o deslocamento da máquina quando não estava aplicando, seja indo ou voltando do local de reabastecimento, ou deslocamento improdutivo. Foram também marcados pontos de importância na área, como por exemplo, o ponto final de trabalho e o de abastecimento.

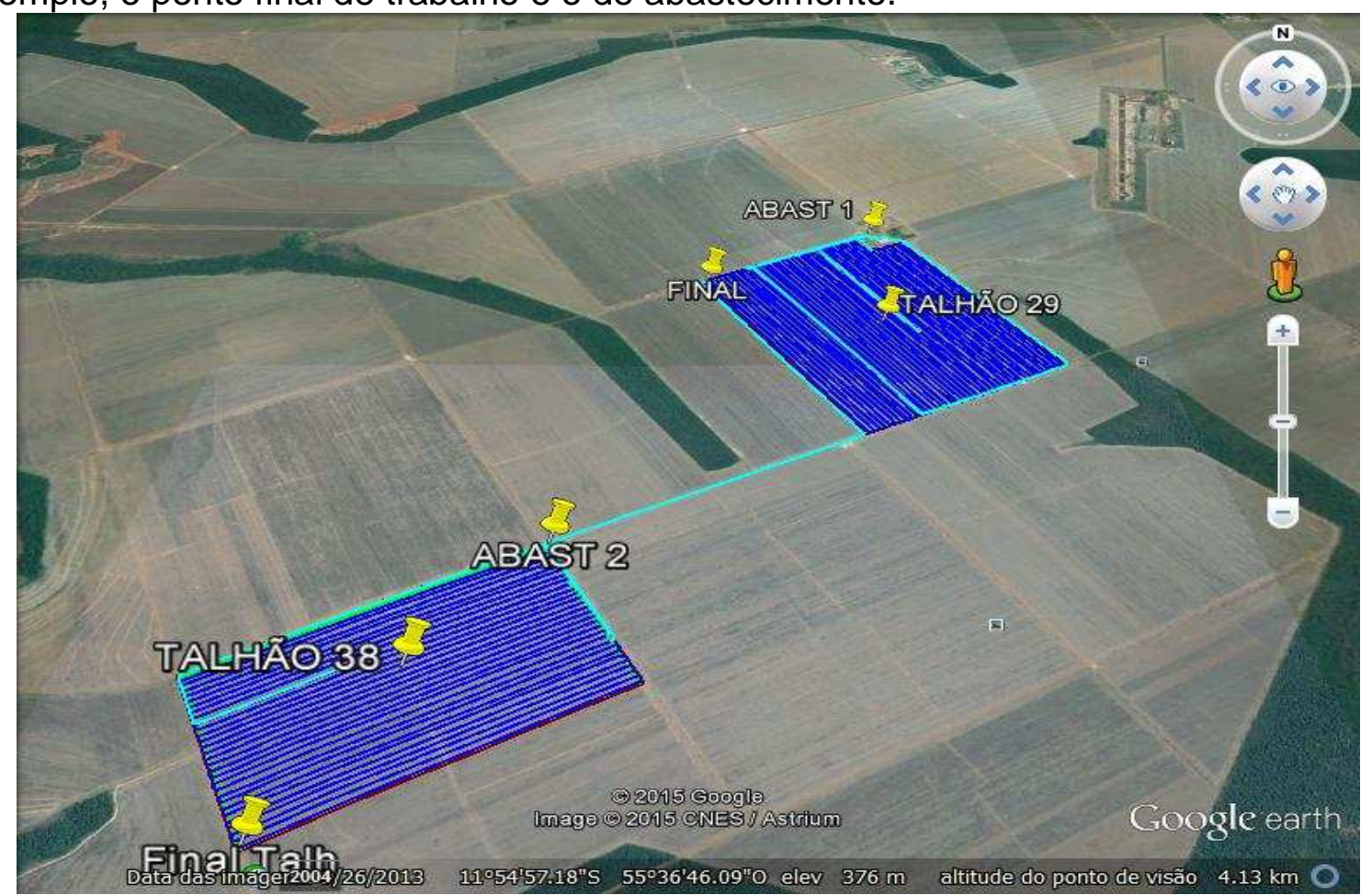

FIGURA 2 - Mapa da atividade de pulverização. Fonte: GOOGLE EARTH ${ }^{\circledR}, 2015$.

Após o tratamento e identificação dos diferentes dados do trabalho, ocorreu a 
análise e discussão dos fatores importantes e decisivos no desempenho da atividade.

\section{RESULTADOS E DISCUSSÃO}

\section{Tempo de Interrupção (TI)}

No tempo onde a máquina teve a sua aplicação interrompida por algum fator do trabalho, cada tipo de interrupção nos talhões é representado a seguir (Figuras 3 e 4).

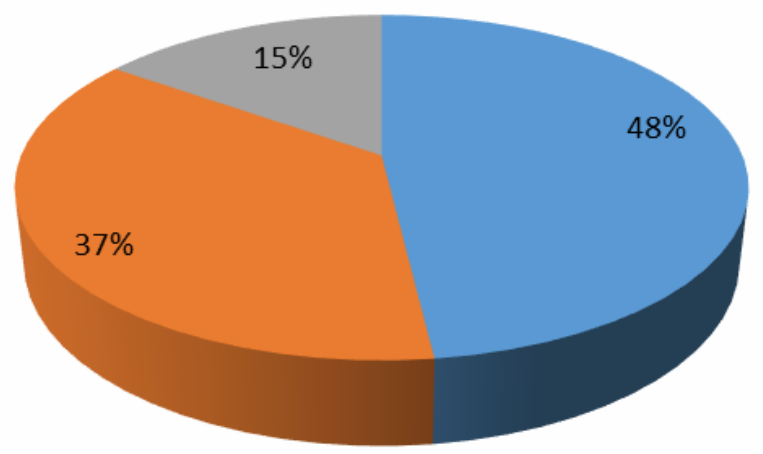

- Tempo de reabast. - $\operatorname{Tr}(\mathrm{h}) \quad \square$ Tempo de deslocamento - $\mathrm{Td}(\mathrm{h})$

- Tempo de virada - Tv $(\mathrm{h})$

FIGURA 3 - As divisões do tempo de interrupção no talhão 29.

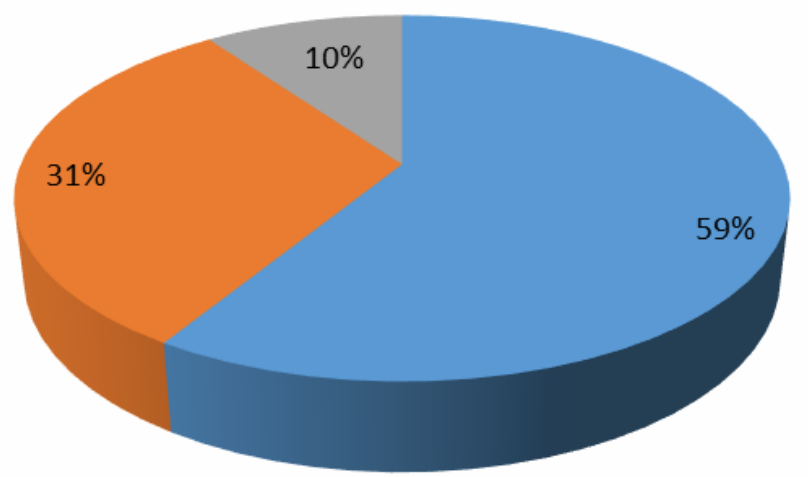

- Tempo de reabast. - $\operatorname{Tr}(\mathrm{h}) \quad \quad \quad$ Tempo de deslocamento $-\operatorname{Td}(\mathrm{h})$

- Tempo de virada - Tv (h)

FIGURA 4 - As divisões do tempo de Interrupção no talhão 38. 
O tempo de deslocamento do pulverizador que é o tempo improdutivo da máquina indo para o reabastecimento e voltando para área de aplicação, foi maior no talhão 29 e acrescentou $37 \%$ no tempo de interrupção (Figura 3), evidenciando que o pulverizador percorreu maior distância para o reabastecimento, comparado com o talhão 38. O tempo de virada onde a máquina faz a volta de cabeceira para a outra faixa de tratamento, é o que menos acrescenta no tempo de interrupção nos dois talhões, com $10 \%$ apenas no talão 38 (Figura 4 ).

O tempo de reabastecimento do tanque de mistura do pulverizador foi o que mais acrescentou ao tempo total de interrupção nos dois talhões, sendo o de maior valor no talhão 38, com 59\% (Figura 4). Pode-se observar que no talhão 29 onde ocorreram quatro reabastecimentos, o tempo de enchimento do reservatório foi menor devido ser realizado com auxílio de uma bomba elétrica de maior vazão, e no talhão 38 onde ocorreram três reabastecimentos os tempos foram maiores (Figura 5), pois eram realizados com uma bomba de menor vazão.

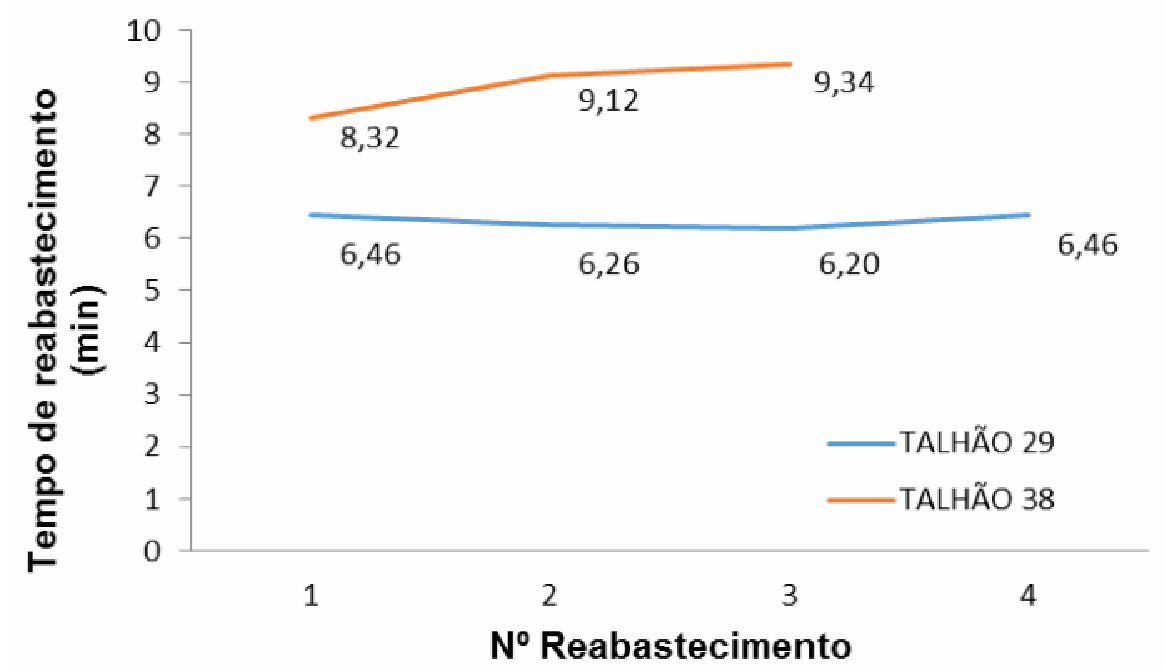

FIGURA 5 - Tempos de reabastecimento do reservatório do pulverizador

Se fosse possível ter a vazão do primeiro local de reabastecimento (470 $\mathrm{L} \mathrm{min}^{-1}$ ) para o segundo talhão da lavoura, o tempo total de reabastecimento diminuiria de 0,45 $\mathrm{h}$ para $0,32 \mathrm{~h}$, ocasionando em um menor tempo de interrupção e melhorando a capacidade operacional. Para uma representação geral do estudo, foi feita a média nos dois talhões para os tempos de interrupções (Figura 6).

O tempo reabastecimento correspondeu ao maior percentual dos tempos de interrupções com 53\%, sendo este podendo ser melhorado com aumento da vazão da bomba de enchimento do reservatório de calda. O tempo de virada ou manobra, correspondeu ao menor tempo de interrupção, justificado por serem áreas planas e de formato regular. 


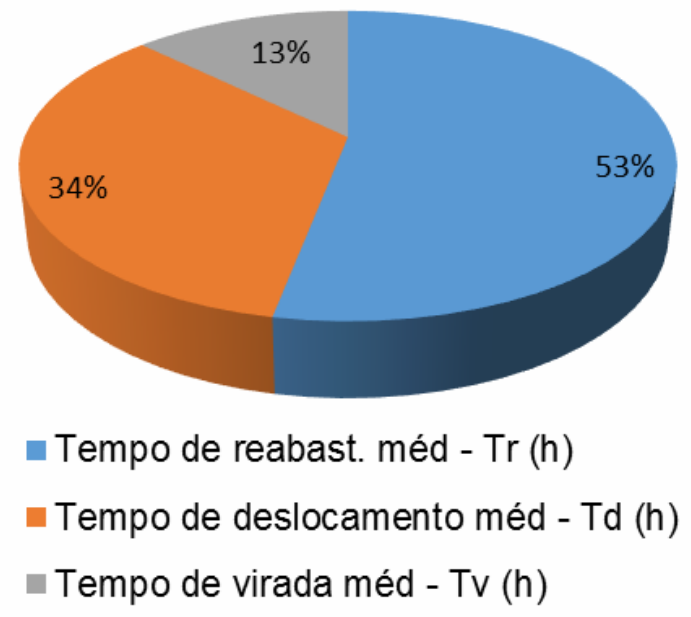

FIGURA 6 - Tempo de Interrupção médio.

\section{Tempo máquina (TM)}

As Figuras 7 e 8 demonstram a composição do tempo máquina, o tempo de produção nos dois talhões foi o que mais contribuiu para o tempo máquina, sendo que no talhão 29 (Figura 7) ele representa maior porcentagem de participação $68 \%$ no tempo total de $3,62 \mathrm{~h}$ ou tempo máquina.

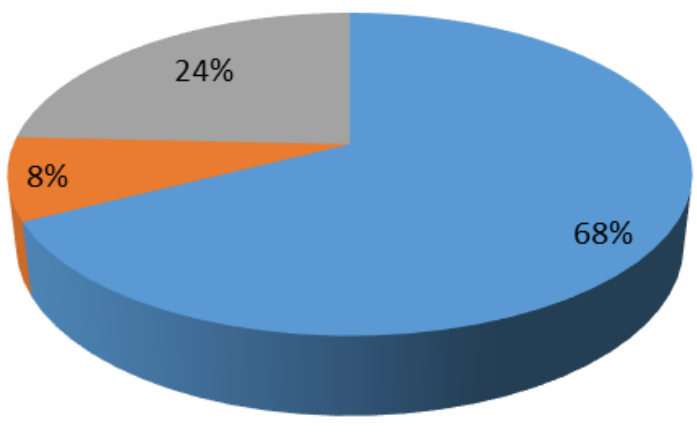

$$
\begin{aligned}
& \text { - Tempo de Produção - TPr (h) } \quad \text { - Tempo de Preparo - Tpe (h) } \\
& \text { - Tempo de Interrupção - TI (h) }
\end{aligned}
$$

FIGURA 7 - Tempo máquina no talhão 29.

O tempo máquina no talhão 38 (Figura 8) ficou evidenciado pela contribuição de $63 \%$ do tempo de produção ou 1,81 h do tempo total. Já o tempo de interrupção neste talhão contribuiu com um percentual maior, com interferência dos fatores comentados anteriormente, como o tempo de abastecimento, que foi responsável também por esse aumento. 


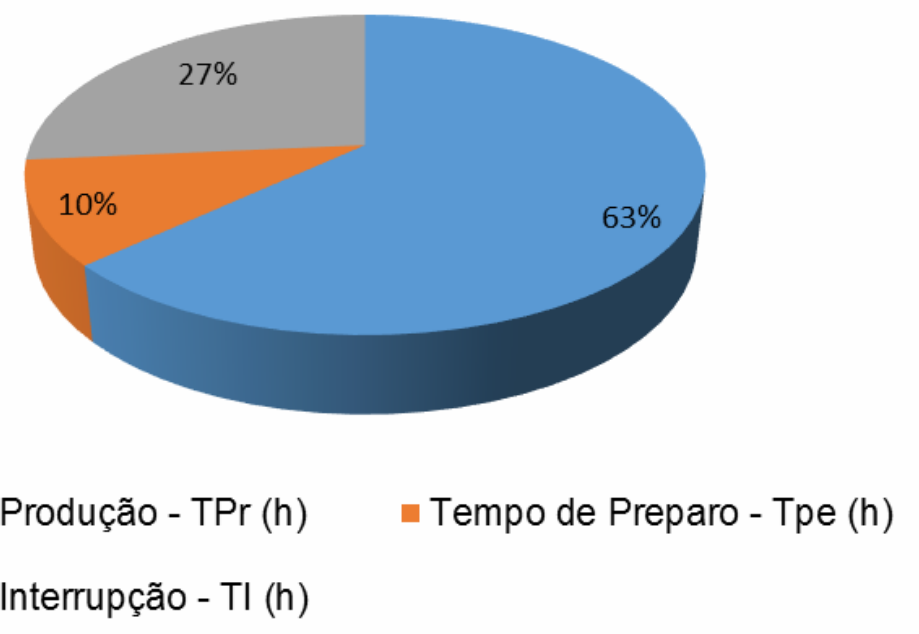

FIGURA 8 - Tempo Máquina no talhão 38.

Nas Figuras 9 e 10 observamos que o tempo de preparo (Tpe) foi muito próximo para ambos os talhões, pois representou apenas o tempo de abastecimento do tanque de combustível no início do dia. Ele apresenta a menor contribuição ao tempo máquina. Isso é facilmente explicado pelo fato de não ter ocorrido limpeza da máquina no dia da aplicação, e o pulverizador já está regulado e calibrado.

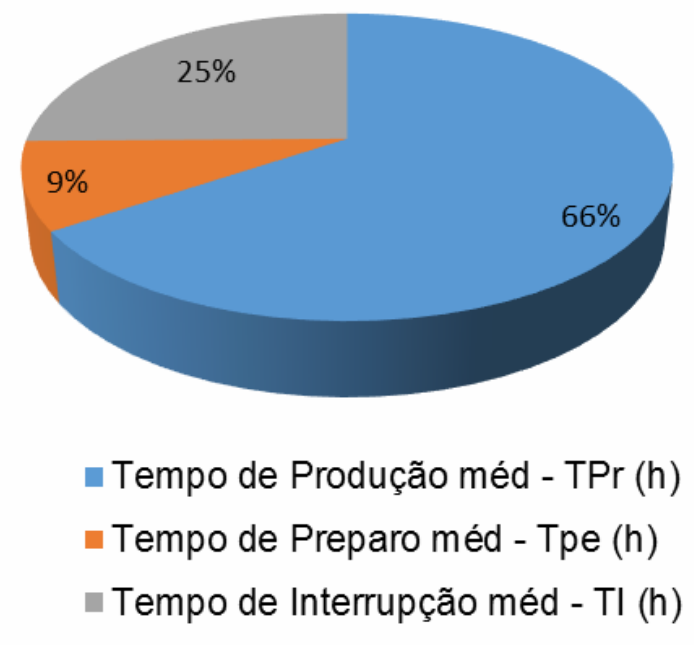

FIGURA 9 - Tempo máquina médio.

Com os dados obtidos em campo, foi calculada a capacidade de campo efetiva e operacional de cada talhão, o rendimento dos mesmos para os dois métodos de cálculo de capacidade de campo operacional e feito uma média entre os talhões 29 e 38 (Tabela 1). 
TABELA 1 - Capacidades de campo e rendimento para os dois tipos de métodos analisados

\begin{tabular}{|c|c|c|c|c|c|c|c|}
\hline \multirow[b]{2}{*}{ Talhão } & \multicolumn{3}{|c|}{ Método 1} & \multicolumn{3}{|c|}{ Método 2} & \multirow{2}{*}{$\begin{array}{l}\text { Dif. } \\
\text { RcE } \\
\text { (\%) }\end{array}$} \\
\hline & $\begin{array}{c}\text { CcE } \\
\left(h^{-1} h^{-1}\right)\end{array}$ & $\begin{array}{c}\mathrm{CcO} \\
\left(\mathrm{ha} \mathrm{h}^{-1}\right)\end{array}$ & $\begin{array}{l}\text { RcE } \\
(\%)\end{array}$ & $\begin{array}{c}\mathrm{CcE} \\
\left(\mathrm{ha} \mathrm{h}^{-1}\right)\end{array}$ & $\begin{array}{c}\mathrm{CcO} \\
\left(\mathrm{ha} \mathrm{h}^{-1}\right)\end{array}$ & $\begin{array}{l}\text { RcE } \\
(\%)\end{array}$ & \\
\hline 29 & 77,66 & 52,39 & 67,46 & 77,66 & 53,33 & 68,67 & 1,80 \\
\hline 38 & 71,25 & 44,94 & 63,07 & 71,25 & 50,42 & 70,75 & 12,2 \\
\hline Média & 74,46 & 48,66 & 65,26 & 74,46 & 51,87 & 69,71 & 6,80 \\
\hline
\end{tabular}

\section{Capacidade de Campo Efetiva (CcE)}

A capacidade de campo efetiva (CcE) (Tabela 1) é o mesmo valor para os dois métodos de cálculo, pois a área de aplicação e os tempos são os mesmos. O talhão 29 obteve a capacidade de campo efetiva de 77,66 ha h$^{-1}$, valor maior que o talhão 38 que foi de $71,25 \mathrm{ha} \mathrm{h}^{-1}$. Essa diferença é explicada, pois, em sua área de aplicação $(189,9$ ha), o pulverizador conseguiu obter um tempo menor de produção $(2,45 \mathrm{~h})$ do que 0 talhão 38, que em uma área de 128,9 ha, o tempo de aplicação foi de 1,81 h.

Alguns fatores estão ligados à diferença de capacidade operacional efetiva, como a velocidade média de aplicação, que para o talhão 29 era de $24,4 \mathrm{~km} \mathrm{~h}^{-1}$, e já para o talhão 38 foi de $22,7 \mathrm{~km} \mathrm{~h}^{-1}$, garantindo que quando a velocidade de aplicação é maior, o pulverizador tende a aplicar um número superior de ha $\mathrm{h}^{-1}$. Isso desconsiderando os fatores de qualidade na aplicação, onde é necessário ter o controle. Para uma média dos dois talhões, a capacidade de campo efetiva foi de $74,40 \mathrm{ha} \mathrm{h}^{-1}$.

\section{Capacidade de Campo Operacional ( $\mathrm{CcO}$ )}

Levando em consideração as condições reais de operação do pulverizador e os efeitos dos fatores operacionais, a capacidade de campo operacional foi calculada para os dois talhões e calculada a média entre eles (Tabela 1). Através do tempo máquina calculado (método 1), a capacidade operacional foi de 52,39 ha $\mathrm{h}^{-1}$ para o talhão 29 , e no talhão 38 o valor de 44,94 ha h$^{-1}$. A capacidade foi maior no primeiro talhão, isso devido aos fatores do tempo máquina que foi discutido anteriormente (Figura 7 e 8), que apesar de o talhão 38 ter uma área aplicada menor o tempo de reabastecimento $e$ o tempo de aplicação tem grande influência na menor capacidade de campo operacional.

Em uma situação proposta anteriormente, o talhão 38 tendo à vazão de reabastecimento a mesma do primeiro local (Figura 5), o tempo de reabastecimento seria menor resultando no aumento da capacidade operacional de 44,94 ha $\mathrm{h}^{-1}$ para 
46,90 ha $\mathrm{h}^{-1}$, sendo possível ter mais dois hectares tratados aproximadamente no mesmo intervalo de tempo.

No primeiro método, a média da capacidade de campo operacional para os dois

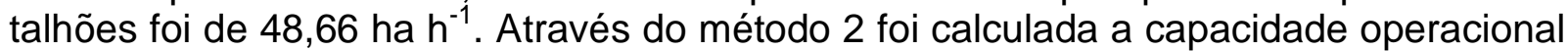
de cada talhão. Para o cálculo dessa capacidade em toda área de aplicação, foram considerados valores médios dos dados coletados em campo. Não são apresentados na equação os tempos de produção, mas sim considerando a velocidade média de produção e o comprimento médio da faixa de tratamento.

A capacidade operacional calculada por esse método de logística conseguiu valores superiores para os dois talhões. No talhão 38 aconteceu a maior diferença, com 5,48 ha $^{-1}$ de diferença (Tabela 1). A média da capacidade de campo operacional dos talhões pelo método 2 de pulverização foi de 51,87 ha $\mathrm{h}^{-1}$. Cada método tem suas características e maneiras de acrescentar os dados coletados, depende das informações essenciais disponíveis para cada situação.

\section{Rendimento de Campo Efetivo (RcE)}

O rendimento para o talhão 29 (Tabela 1) ficou muito próximo em relação aos dois métodos de cálculos com variação de 1,8\%. Já o talhão 38 apresentou uma diferença de $12,2 \%$, com $70,75 \%$ de rendimento para a logística de pulverização e $63,07 \%$ para 0 primeiro método. Foi considerado um rendimento médio para cada tipo de método, para um melhor resultado do trabalho.

Segundo ASAE (1999) a eficiência de campo ou rendimento para pulverizador de barra está entre 50 e $80 \%$. O rendimento do método 1 de cálculo foi de $65,26 \%$, comparando com o rendimento determinado pela norma da ASAE (1999), o valor está dentro do indicado. Pelo método 2 o rendimento médio foi $69,71 \%$, que também está dentro da faixa de rendimento, mesmo tendo um valor superior.

\section{CONCLUSÕES}

O tempo gasto para reabastecimento do reservatório do pulverizador, seguido do tempo de deslocamento para reabastecimento, representaram uma alta influência no tempo de interrupção da aplicação, sendo os mais impactantes.

A vazão da bomba de reabastecimento do reservatório do pulverizador foi o que mais influenciou na capacidade operacional. Os dois métodos de cálculo da capacidade de campo operacional podem ser usados dependendo da precisão dos cálculos que se tenha necessidade. O rendimento de campo operacional ficou dentro do recomendado, mas ainda podendo ser melhorado.

\section{REFERÊNCIAS}

ASABE. Agricultural Machinery Management Data (ASAE D497.4). American Society of Agricultural and Biological Engineers. St. Joseph, 1999.

BAIO, F. H. R.; ANTUNIASSI, U. R.; BALASTREIRE, L. A.; FILHO, J. V. C. Modelo de programação linear para seleção de pulverizadores agrícolas de barras. Engenharia Agrícola, Jaboticabal, v.24, n.2, p.355-363, 2004.

COSTA, M. F. Tecnologia de aplicação de defensivos agrícolas. Universidade ENCICLOPÉDIA BIOSFERA, Centro Científico Conhecer - Goiânia, v.11 n.22; p.886 
Federal de Mato Grosso. 2009.118 p.

JOHN DEERE. Pulverizador Autopropelido 4730, 2015. In:

<http://www.deere.com.br/pt_BR/docs/html/brochures/publication.html?id=719d33e7\#1 Acesso: 07/06/2015.

JUNIOR, E. B.; FERREIRA, M. C.; LEITE, G. J. Avaliação da pulverização de calda herbicida em cana soca por meio de diferentes equipamentos, declives e horários de aplicação. Conbraf - Congresso Brasileiro de Fitossanidade, UNESP. Jaboticabal. 2013.

MATUO, T. Técnicas de aplicação de defensivos agrícolas. Jaboticabal, FUNEP, 1990. 139p.

MIALHE, L. G. Manual de mecanização agrícola. São Paulo: Agronômica Ceres, 1974. 301p.

PERES, A. J. A. Volume de aplicação na qualidade da deposição da pulverização na cultura do algodoeiro. Universidade Estadual Paulista "Júlio de Mesquita Filho". 2014. 55 f. Dissertação (Mestrado em Agronomia). Botucatu, 2014.

VIEIRA, R. R. Tempo de resposta de um controlador eletrônico em sistemas de aplicação a taxas variáveis em pulverizadores agrícolas. 2013. 79 f. Dissertação (Mestrado em Ciências). Universidade de São Paulo (Escola Superior de Agricultura "Luiz de Queiroz"). Piracicaba, 2013. 